\title{
Effects of Damping Plate and Taut Line System on Mooring Stability of Small Wave Energy Converter
}

\author{
Zhen Liu, ${ }^{1,2}$ Ying Cui, ${ }^{3}$ Huanyu Zhao, ${ }^{3}$ Hongda Shi, ${ }^{1,2}$ and Beom-Soo Hyun ${ }^{4}$ \\ ${ }^{1}$ Shandong Provincial Key Laboratory of Ocean Engineering, Ocean University of China, Qingdao 266100, China \\ ${ }^{2}$ Qingdao Municipal Key Laboratory of Ocean Renewable Energy, Ocean University of China, Qingdao 266100, China \\ ${ }^{3}$ College of Engineering, Ocean University of China, Qingdao 266100, China \\ ${ }^{4}$ College of Ocean Science and Technology, Korea Maritime and Ocean University, Busan 404796, Republic of Korea
}

Correspondence should be addressed to Zhen Liu; liuzhen@ouc.edu.cn

Received 17 April 2015; Accepted 17 June 2015

Academic Editor: Ming Zhao

Copyright (C) 2015 Zhen Liu et al. This is an open access article distributed under the Creative Commons Attribution License, which permits unrestricted use, distribution, and reproduction in any medium, provided the original work is properly cited.

\begin{abstract}
Ocean wave energy can be used for electricity supply to ocean data acquisition buoys. A heaving buoy wave energy converter is designed and the damping plate and taut line system are used to provide the mooring stability for better operating conditions. The potential flow assumption is employed for wave generation and fluid structure interactions, which are processed by the commercial software AQWA. Effects of damping plate diameter and taut line linking style with clump and seabed weights on reduction of displacements in 6 degrees of freedom are numerically studied under different operating wave conditions. Tensile forces on taut lines of optimized mooring system are tested to satisfy the national code for wire rope utilization.
\end{abstract}

\section{Introduction}

The resource of fossil fuel on land has been reducing significantly and rapidly because of the huge demand and consumption of energy in the economy development. Ocean contains abundant energies such as wave, tidal stream, and thermal energy. For instance, wave energy resource for technical exploitation is up to 0.1 to $1 \mathrm{TW} \cdot \mathrm{h} /$ year, which is of the same order of magnitude of world electricity consumption. Wave energy has become one of the most popular research areas, which is also quite different from traditional ocean engineering $[1,2]$. The fluid structure interaction is more violent for most of wave energy converters during their operating stage. Besides the power take-off mechanism, the mooring system and stability analysis of floating oscillating body wave energy converter have attracted many scholars' interests $[3,4]$.

Originally, the mooring system of floating marine structures was designed and investigated for drilling platforms and offshore wind turbines. A new hybrid mooring system was designed to reduce the tension on the lines and is widely used in various water depths [5]. It is indicated that the hybrid mooring system with weights and buoys shows better performance than the taut mooring system and the hybrid mooring system only with weights. The catenary mooring system design for tri-floater floating offshore wind turbines was designed by Benassai et al. [6]. Both ultimate and accidental limit states are examined by wave loads under 50 and 1 year return period conditions. It is found that platform admissible offset and line pattern significantly influence the mooring system weight. Obtained results show that 9 and 12 line configurations are the necessary choice and the mooring line weight is independent of water depth between 100 and $200 \mathrm{~m}$, or it will increase if the water depth is out of this range.

The catenary and vertical tensioned mooring lines are then numerically studied for the mooring control of trifloater support structures for wind turbines [7]. Numerical investigations of dynamic response of a spar-type hollow cylindrical floating substructure moored by three catenary cables to irregular wave excitation were conducted [8]. The wave-floating substructure and wave-mooring cable interactions are simulated by coupling BEM and FEM in the staggered iterative manner under potential wave flow conditions. The modeling of mooring systems and structural behavior of floating vertical axis wind turbines and various 
mathematical models with their suitability for developing model of coupled dynamics are summarized [9].

For the studies of mooring system for wave energy converters, the field sea trials and physical model tests can provide valuable information and validation for the numerical models. An approach is proposed to calculate and predict the fatigue damage of the mooring system [10]. Corresponding loads are measured in the large-scale field trials at the South West Mooring Test Facility. The mooring system which warrants the stability-keeping of marine energy devices is subject to highly cyclic, nonlinear load conditions mainly induced by the incident waves. Experiments were conducted on a 1:20 scale model of the floating wave energy device moored by six mooring lines to study the dynamics of the device under regular waves for various scopes [11], which was intended to provide a better understanding of the hydrodynamic behavior of a floating multiresonant oscillating column wave energy device which combines the concept of a floating breakwater and a wave energy device. Several wave tank test results for a scale model of the buoy and mooring used at the South West Mooring Test Facility were presented for the validation of a time-domain mooring modeling tool to check the buoy draft and the tension characteristics of the mooring system [12].

Within the development of the computation capability and numerical models, the mathematical models for analysis of mooring system and stability characteristics become popular and useful in the wave energy field. A method to include the influence of mooring cables in the frequency domain analysis of wave energy converters was proposed to be applied to a generic wave energy device based on a truncated vertical cylinder of 100 ton displacement [13]. An array of identical floating point absorbers located at the grid points of an equilateral triangular grid was considered by Fitzgerald and Bergdahl [14]. The whole system buoys, moorings, and power take-off systems are assumed to be linear and a frequency domain analysis was employed. An approach for extrapolating 50-year extreme load responses was used for extreme wind load estimations, which was transferred for wave loads acting on floating wave energy converters; extreme tension loads with a return period of 50 years and impact given failure are assessed for the hawser and at the different mooring lines [15].

Most previous published researches focused on the mooring system of large ocean engineering structures such as oilrig platforms, wind turbines, and high installed capacity wave energy converters. The present paper deals with the small heaving body wave energy converter (WEC) within $1 \mathrm{~kW}$ level electricity generation, which is supposed to be used for long-term energy supply for offshore ocean environmental monitoring devices, such as the ocean buoys. The design of WEC mainly includes the energy converting and mooring systems. The station-keeping capability and low costs demands are considered together. Numerical model based on the commercial software Ansys-AQWA is applied for the fluid structure interaction analysis. Effects of the damping plate and taut line system on stability are studied and engineering application of the optimized design is scheduled as the sea trial proofs.

\section{Design of $1 \mathrm{~kW}$ Heaving Body Wave Energy Converter}

Long-term independent electricity supply of offshore ocean data acquisition buoys has proposed the demands for in situ power take-off, which can be satisfied by wave energy converters within suitable electricity cable connection approaches. Since the electricity request is not high, $1 \mathrm{~kW}$ installed capacity is enough for everyday and long-term supply. On the other hand, the wave energy converter is considered to be operated around nearshore sea area in China, where the flux density of wave energy is significantly smaller than that in the Atlantic. This ideal was initially supported by the Special Fund Project for Ocean Renewable Energy, which was granted by State Oceanic Administration of Chinese center government.

Following the above conditions and demands, the design principle of the small wave energy converter for ocean buoys electricity supply, located in Qingdao, China, should be the following:

(i) $1 \mathrm{~kW}$ installed capacity with high reliability energy converting mechanism (project evaluating indicator).

(ii) Away from coastline: $\leqslant 50 \mathrm{~m}$, water depth: $\leqslant 20 \mathrm{~m}$, operating wave height: $0.5 \mathrm{~m}$, extreme wave height: $1.4 \mathrm{~m}$, and wave period: $3.0 \sim 7.0 \mathrm{~s}$ (derived from local measured data).

(iii) High stability of mooring system: heave less than $0.1 \mathrm{~m}$, surge and sway less than $0.2 \mathrm{~m}$, and pitch, roll, and yaw less than $10^{\circ}$ under operating wave conditions (project admissible values).

(iv) Low costs on manufacturing, transportation, and deployment.

(v) Easy access to repairing and maintenance.

The $1 \mathrm{~kW}$ heaving body wave energy converter is illustrated in Figure 1. The buoy could heave along the guide rod, which restricts the buoy's oscillation in one degree of freedom (DOF). The guide rod is long enough to adapt the tidal difference and is connected by two-sided rack and gear system within the buoy. Especially for the small installed capacity, the rack-gear system is regarded to be more effective and efficient than other energy converting types, such as the linear generator and hydraulic pressure system. The gear also links with the electricity generator using the bearing and speed-growth devices. All the above units are fixed in the watertight compartment arranged into the buoy. A hollow damping plate is installed underwater to provide the stability and buoyancy of equipment except for the buoy (mooring system). Four piles are used to connect the seabed weights and the damping plate employing taut lines. Clump weight is at the end of the guide rod to lower the gravity center.

\section{Numerical Model}

3.1. Governing Equations. Linear wave is considered based on the assumption of homogeneous, incompressible, inviscid fluid and irrotational flow. In addition, the wave amplitude is assumed to be small compared to the wave length and water depth; hence, the linear free surface condition is used. In the 


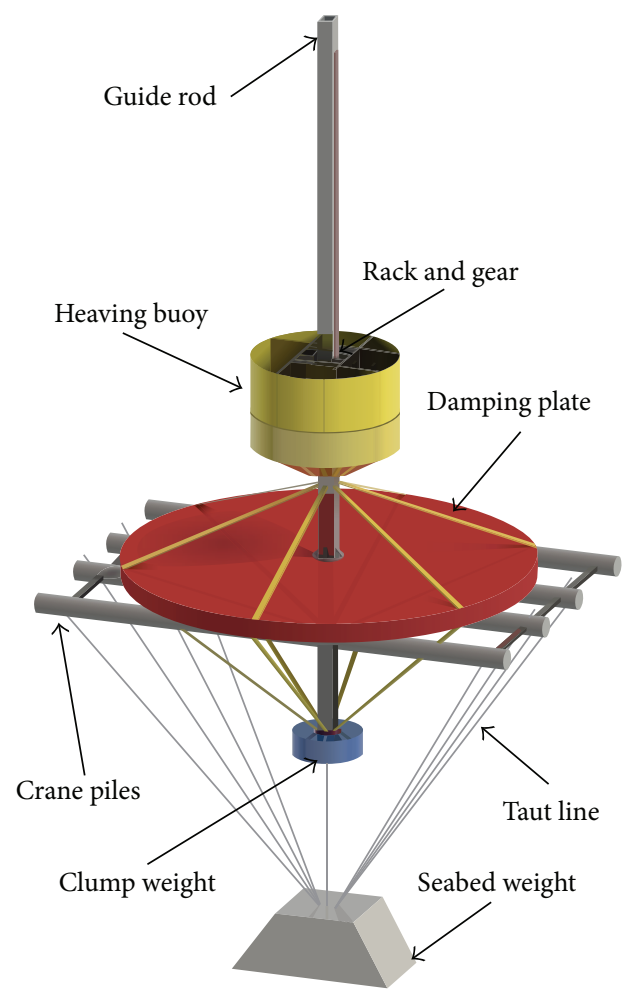

FIGURE 1: Schematic of $1 \mathrm{~kW}$ heaving body wave energy converter.

Cartesian coordinate system, the velocity potential, velocity, and free surface elevation can be expressed as

$$
\begin{aligned}
& q(x, y, z, t)=\operatorname{Re}\left\{u(x, y, z) e^{-i \omega t}\right\}, \\
& \zeta(x, y, z, t)=\operatorname{Re}\left\{\eta(x, y) e^{-i \omega t}\right\}, \\
& \Phi(x, y, z, t)=\phi(x, y, z) e^{-i \omega t},
\end{aligned}
$$

where $u(x, y, z)=\nabla \varphi(x, y, z), q$ is the fluid particle velocity, $\omega$ is the wave frequency (in $\mathrm{rad} / \mathrm{s}$ ), $\zeta$ is the surface elevation, and $\Phi(x, y, z, t)$ is the velocity potential. The origin of the reference is at the still water surface. The orientation of the vertical axis $z$ is upward.

By accounting for wave radiation and diffraction, the fluid structure interaction behavior is described by the set of equations

$$
\text { Laplace equations: } \nabla^{2} \Phi(x, y, z, t)=0
$$

applicable everywhere in the fluid domain. Consider

Linear free surface boundary: $\frac{\partial^{2} \Phi}{\partial t^{2}}+g \frac{\partial \Phi}{\partial z}=0$,

Body surface conditions: $\frac{\partial \Phi}{\partial n}=U_{j} \widetilde{n}_{j}$,

Seabed surface condition at depth of $H:\left.\frac{\partial \Phi}{\partial n}\right|_{z=-H}$ $=0$.
Radiation conditions are as follows. Wave propagation could be found far from the body surface. $U_{j}$ is the generalized velocity of body surface, $\tilde{n}_{j}$ is the generalized normal vector of the specific point on the body surface, and subscript $j$ is the $j$ th mode of motion of the above components.

The velocity potential could be expressed by using superposition principle as follows:

$$
\begin{aligned}
\Phi(x, y, z, t)= & \Phi^{I}(x, y, z, t)+\Phi^{D}(x, y, z, t) \\
& +\Phi^{R}(x, y, z, t)
\end{aligned}
$$

where $\Phi^{I}(x, y, z, t)$ is the incident wave potential, $\Phi^{R}(x, y$, $z, t)$ is the radiation potential, and $\Phi^{D}(x, y, z, t)$ is the diffraction potential, respectively. In addition, $\Phi^{D}+\Phi^{R}=\Phi^{P}$, which are called the disturbing potential together.

Assuming that the body motion is small around the still water surface, the velocity potential $\Phi(x, y, z, t)$ could be expressed as

$$
\Phi(x, y, z, t)=\operatorname{Re}\left\{\phi(x, y, z) e^{-i \omega t}\right\}
$$

where $\phi(x, y, z)$ can be called the isolated space dependent potential. The solution could be regarded as a steady problem, which is expressed as

$$
\phi(x, y, z)=\phi^{I}(x, y, z)+\phi^{D}(x, y, z)+\phi^{R}(x, y, z),
$$

where $\phi^{I}$ is the incident wave velocity potential at a single direction within a single frequency. It can be resolved by the following equation:

$$
\phi^{I}=-\frac{A g}{\omega} \frac{\cosh k(z+h)}{\cosh k h} \exp [i k(x \cos \beta+y \cos \beta)],
$$

where $A$ is the wave amplitude, $k$ is the wave number, $h$ is the water depth, $g$ is the gravity acceleration, $\lambda$ is the wave length, and $\beta$ is the included angle between the incident wave direction and the $x$ axis. $k$ can be defined as $2 \pi / \lambda$, which is calculated by the free surface and water depth conditions.

In order to derive the motion of the system motion in six degrees of freedom, the motion equation of the floating body in the time domain should be considered and expressed as follows [16]:

$$
\begin{aligned}
& (M+m) \ddot{X}(t)+\int_{-\infty}^{t} K(t-\tau) \dot{X}(t) d \tau+C X(t) \\
& =F_{w}(t)+F_{\text {wind }}+F_{c}+F_{\text {sn }}(t)+F_{m}(t),
\end{aligned}
$$

where $X(t)$ represents the transit translation displacement in three directions ( $x, y$, and $z$ axes). $M$ and $m$ are the generalized mass matrix and added mass matrix. $K(t-\tau)$ is the delay function of the system and $C$ is the hydrostatic restoring force coefficient matrix. $F_{w}(t), F_{\text {wind }}, F_{c}, F_{\text {sn }}(t)$, and $F_{m}(t)$ are the first-order wave force, wind force, current force, second-order wave force, and tension loads on taut lines in the corresponding directions, respectively. In this study, wind and current forces are ignored regarding the measured data of local sea areas, so only the wave forces are considered. 
First-order wave force can be resolved from the convolution relationship between the wave force on the frequency and time domains proposed by Cummins. The equation is expressed as

$$
\begin{aligned}
& F_{w i}(t)=\int_{0}^{t} h_{i}^{1}(t-\tau) d \tau \\
& h_{i}^{1}(t)=\frac{1}{\pi} \int_{0}^{\infty} H_{i}^{1}(\omega) e^{i \omega t} d \omega
\end{aligned}
$$

where $H_{i}^{1}$ is the responding function of the first-order regular wave force of the unit amplitude.

The calculation of second-order wave force could be conducted using the method proposed by Newman. Based on the indirect time domain method, after the Fourier transform, the delay function can be expressed as

$$
K_{i j}(t)=\frac{2}{\pi} \int_{0}^{\infty} \lambda_{i j}(\omega) \cos (\omega t) d \omega,
$$

where $\lambda_{i j}$ is the damping matrix of the floating body in the frequency domain.

Added mass in the time domain can be expressed as

$$
m_{i j}=u_{i j}\left(\omega_{0}\right)+\frac{1}{\omega_{0}} \int_{0}^{\infty} K_{i j}(t) \sin \left(\omega_{0} t\right) d t,
$$

where $u$ is the added mass matrix of the floating body in the frequency domain and $\omega_{0}$ is random number.

3.2. Numerical Solutions. Ansys-AQWA is the commercial computational fluid dynamics software based on the governing equations described in Section 3.1. All the calculations of the above equations are coupled in two modules for the final analysis. AQWA-LINE deals with the applications of diffraction and radiation theories for fluid structure interaction [17]. The modules can also calculate the first- and second-order wave forces on the floating structures and further response. In addition, AQWA-NAUT conducts the calculations for hydrodynamic parameters in the time domain under the specific wave conditions [18]. The module will call the added mass, radiation damping, and diffraction force from AQWALINE during the computations. The motion response of the floating structures will be outputted after integrating effects of hinges and anchor lines among bodies. AQWA-NAUT also recalculates the Froude-Krylov force during every time step, considering influences of wet surface area variation on the nonlinear dynamics.

All the structures and grids will be generated in Ansys Mechanical APDL software and then transferred as the AQWA executive files. In the present paper, the scheme in the numerical model is slightly simplified where the crane piles are cancelled and the buoy is fixed on the guide rod without any relative motions. Some corresponding parameters are shown in Figure 2(a); the water depth is fixed as $10 \mathrm{~m}$ and the buoy diameter and height are $1.8 \mathrm{~m}$ and $0.95 \mathrm{~m}$, respectively. The taut lines linking the damping plate and the seabed weights are called SWL and those linking the clump and seabed weights are defined as CWL. The diameter of the damping plate is $D$ and the distance between two seabed weights is $S$. The total weight of the floating facility is around 8 ton. For different shape parameters in the following calculating cases, the height of clump weight, $h_{w}$, the height of the guide rod between the damping plate and clump weight, $h_{G}$, and height of damping plate, $h_{p}$, are adjusted, which will keep the system center of gravity $50 \mathrm{~mm}$ below the top of clump weight. The center of buoyancy is kept at the center of the damping plate using the same method. The net buoyancy is around $4.5 \sim 9.8 \mathrm{kN}$. It should be noted that two CWLs and twin seabed weights will merge to be one line and one weight when $S=0$. The diameter of wire rope used as the taut line is $14 \mathrm{~mm}$ and its elasticity modulus is $206 \mathrm{GPa}$. Following the Chinese code of wire ropes, the allowed maximum tensile force is $138 \mathrm{kN}$ [19].

The grid structures in the numerical model are shown in Figure 2(b); the node number is up to 3074. Shell 181 element is utilized to generate all the nonline structures. Each element has four nodes with $6 \mathrm{DOF}$, which also can degenerate to the triangular elements. Pipe 16 element, which has two nodes, is used for taut lines model setup. The origin of coordinates locates at the intersection of the center axis of the wave energy converter and still water surface. The orientations of $x, y$, and $z$ axes follow the directions shown in Figure 2(b). In the software, the wire rope extensions will be conducted automatically at the start of analysis because of the equilibrium of resultant force at rest. Based on the modulus of elasticity and several trials following the software manuals, wire ropes are all shortened to $95 \%$ of the required lengths considering taut effects as line pretensions, which will make system components get to the preset positions in the preliminary design. The incident wave period $T$ varies from $3.0 \mathrm{~s}$ to $7.0 \mathrm{~s}$. $H=0.5 \mathrm{~m}$ is utilized as the operating wave height; $H=1.4 \mathrm{~m}$ is the extreme wave condition. The time step used in all the calculations is $0.05 \mathrm{~s}$.

3.3. Experimental Validation. In order to validate the capability of the present numerical model on floating body motion under wave excitation, experimental data of the oscillating motion of the buoy are used for the validation. The buoy is restricted to move in one degree of freedom along the guide rod without any damping plates, which is fixed to the tank bottom. All the physical model tests were carried out in the wave tank of Shandong Provincial Key Laboratory of Ocean Engineering, Ocean University of China [20]. Regular waves with different conditions are employed in the experiments. Although the experimental contents are somehow different from the WEC system in the present paper, the validation of buoy's 1D motions still could provide solid evidence explicitly on the capability of the numerical model on the hydrodynamic characteristics of floating bodies driven by waves.

Comparisons between the numerical and experimental results of the buoy heaving amplitudes are shown in Figure 3. Numerical model slightly overpredicts all the results because of the ideal conditions and ignoring all nonlinear effects. Mean error of the numerical predictions is $8.9 \%$. Good agreements show that the numerical model could be applied 


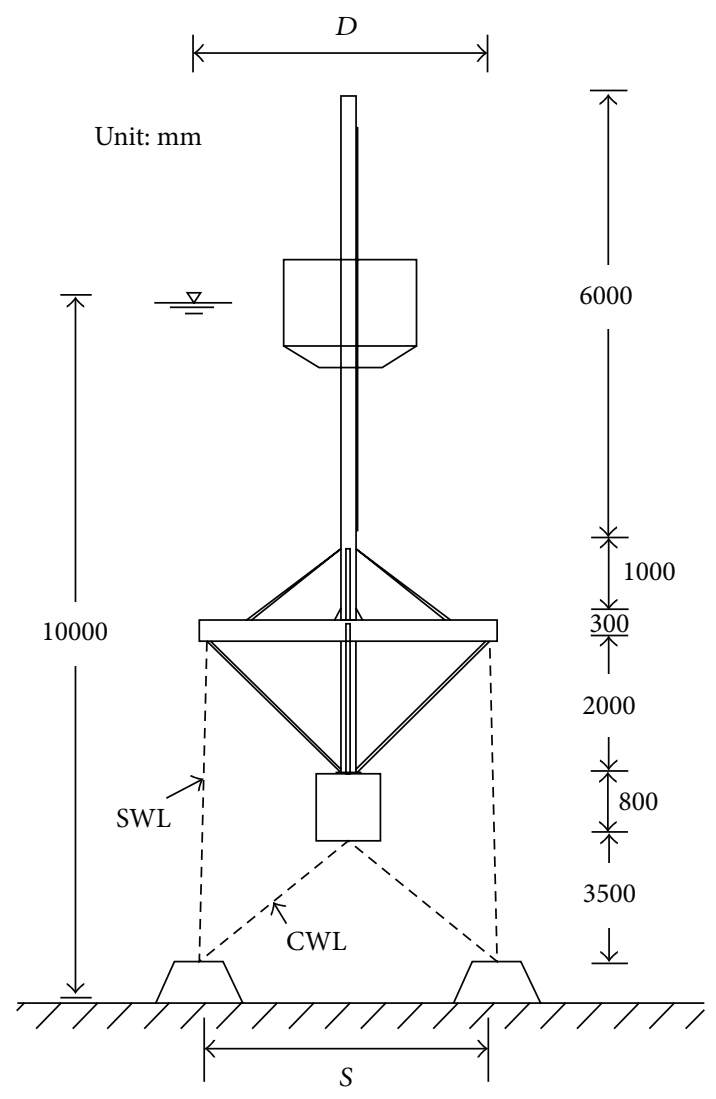

(a) Parameters of WEC

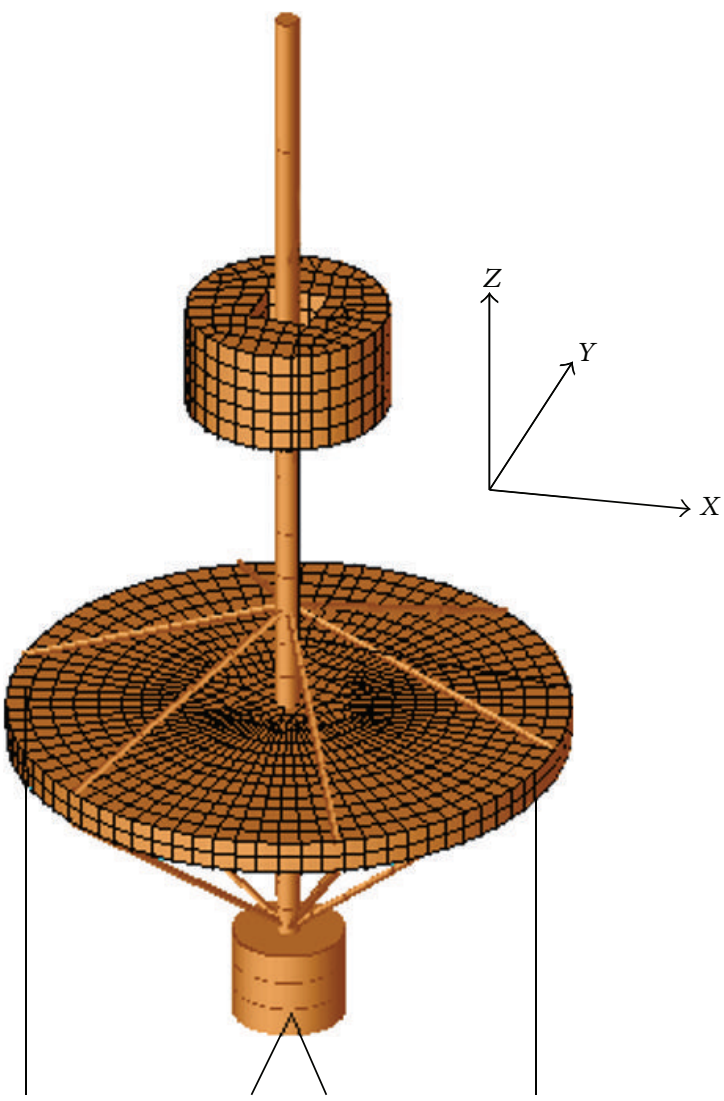

(b) Structure and grids in the numerical model (snapshot from the software)

FIGURE 2: Numerical model setup of WEC with mooring system.

in the further investigation for wave-structure interaction analysis. It also should be pointed out that the mooring line dynamic mechanics are not verified here, which can be referred to the software manual and calculation examples [16-18].

\section{Results and Discussion}

For the mooring system of heaving type point absorber wave energy converter, it is very important to keep the whole facility in stationary state, which will provide a better operating condition for the buoy to oscillate along the guide rod. Hence, the displacements in the six degrees of freedom will be treated as the evaluating indexes in the present paper. The damping plate and the taut line system are designed and tested to reduce the movements in 6 DOF. Time histories of the mooring system displacements and tensile forces of taut lines are demonstrated first. Effects of damping plate diameter, taut line number, and mooring types are then studied. Based on the above investigation results, tension loads under the extreme wave conditions are calculated to verify the safety of wire ropes as taut lines.

4.1. Time History Data Analysis. A typical case of the mooring system is used for time domain results demonstration. The incident waves come from left side. The diameter of damp

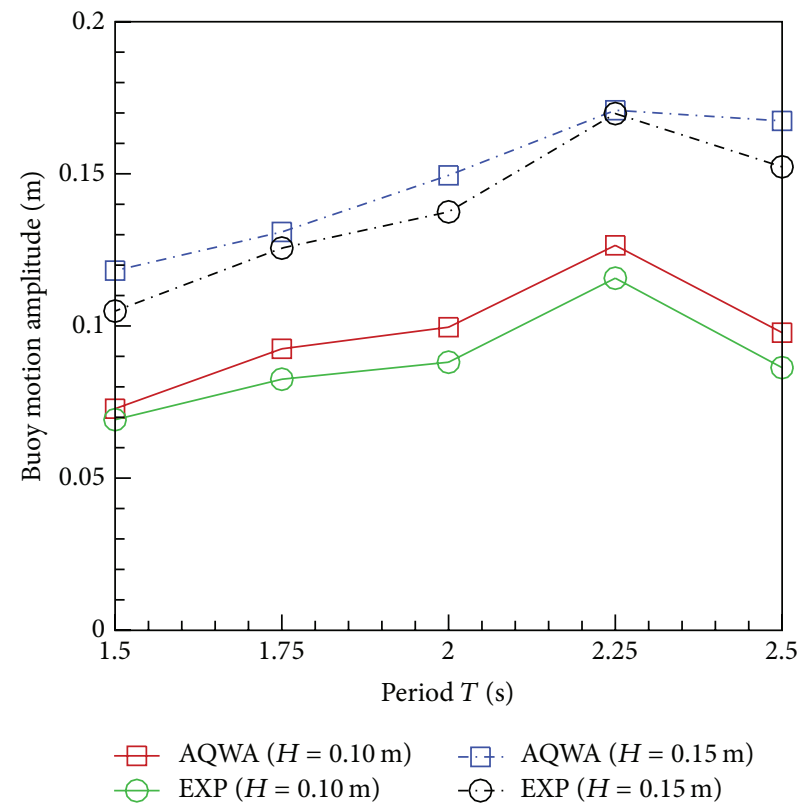

FIgURE 3: Comparison between experimental and numerical heaving amplitudes of the buoy.

plate is $D=5.0 \mathrm{~m}$. Two SWLs and two CWLs are linked to the twin seabed weights, and the ratio $S / D=1.0$. The incident 


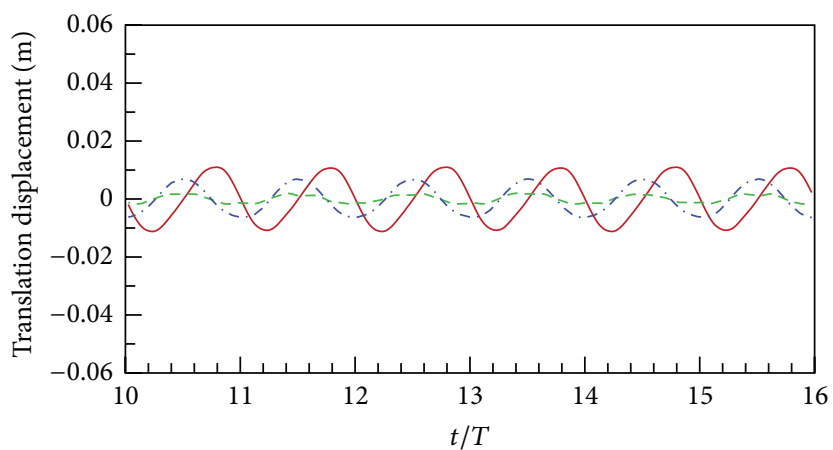

$\begin{array}{ll}\text { — } & \text { Surge } X \\ \text { - - } & \text { Sway } Y \\ \ldots . . & \text { Heave } Z\end{array}$

(a) Translation displacement

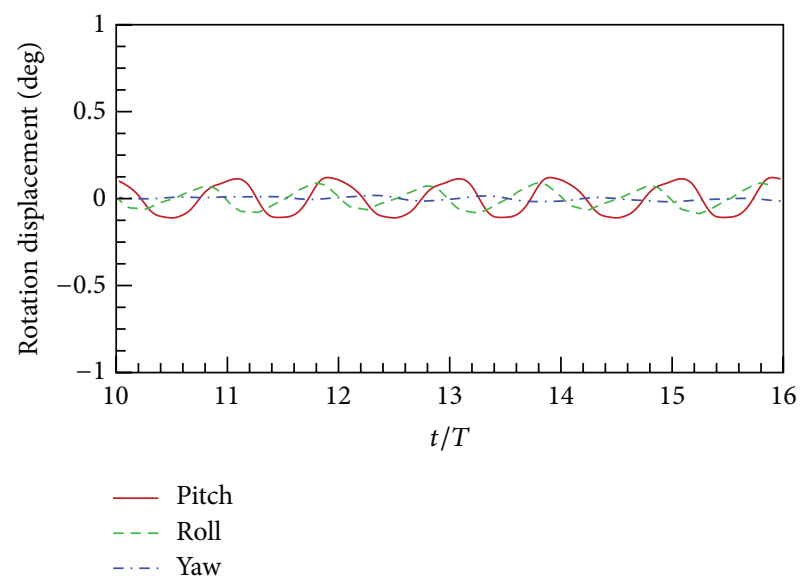

(b) Rotation displacement

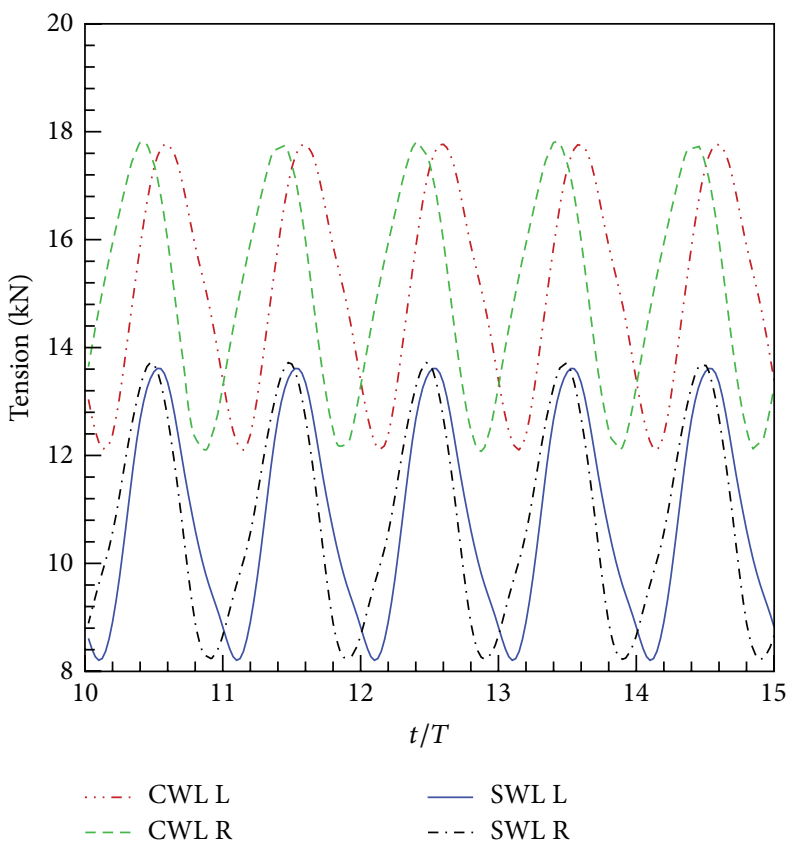

(c) Tension forces on various taut lines

Figure 4: Time histories of mooring system motions and forces $(H=0.5 \mathrm{~m}, T=4.0 \mathrm{~s}, D=5.0 \mathrm{~m}$, and $S=5.0 \mathrm{~m}, 2 \mathrm{CWLs}, 2 \mathrm{SWLs})$.

wave height and period are $H=0.5 \mathrm{~m}$ and $T=4.0 \mathrm{~s}$, respectively. Time histories of translation and rotation displacements of the system center of gravity and tensile forces on taut lines are displayed in Figure 4. The data are derived from the timing when initial incident wave effects disappear.

It can be seen in Figure 4(a) that the translating motion varies in the sinusoidal pattern under regular waves. The amplitudes reduce in order of surge, heave, and sway. It can be seen that the amplitudes of swaying motions are quite small and less than $2.0 \times 10^{-3} \mathrm{~m}$ because of the wave incident direction. Heaving and surging motions under incident wave forces are dominated in the translation movement. Their peak-to-valley values are significantly smaller than the criteria values. For the rotation displacement in Figure 4(b), rotations around three axes demonstrate the quasi-sinusoidal and resilient pattern. All the amplitudes are less than 1 degree. The rotating values in other calculated cases are also very small, which indicates that rotation displacement does not have to be treated as the control elements in the further analysis for the mooring stability.

The variations of tensions on four taut lines are illustrated in Figure 4(c). The positions of two pairs of taut lines in Figure 2(a) are defined following the incident wave directions. The patterns of four curves are all sinusoidal under regular wave conditions. Phase differences of curves are decided by the mooring system movements in 6 DOF. Furthermore, tension forces on two CWLs are evidently larger than that of SWLs and should be used as the checking lines. 


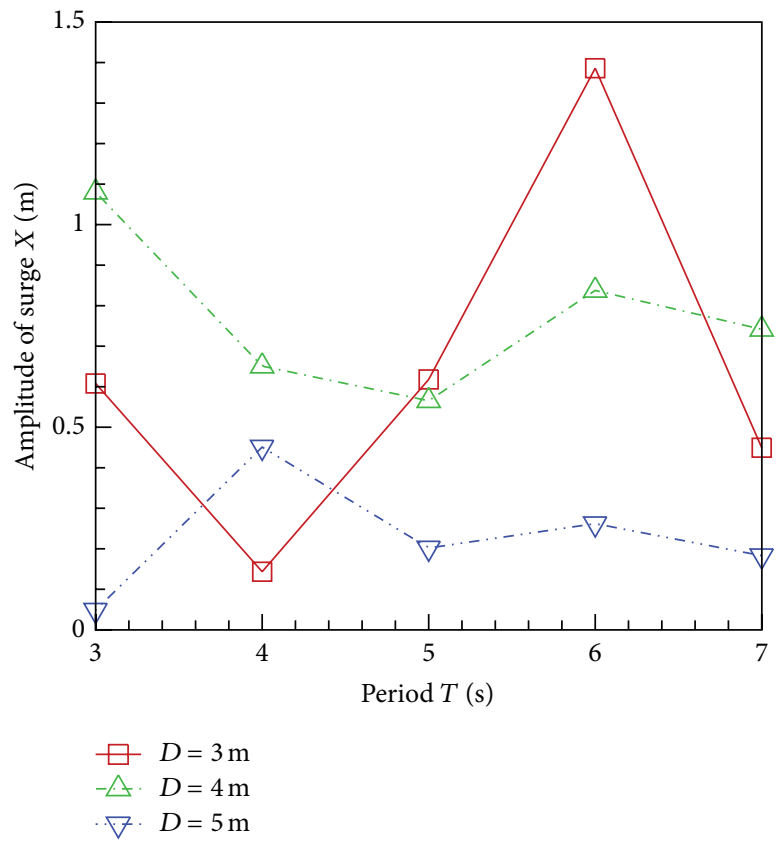

(a) Surge $X$

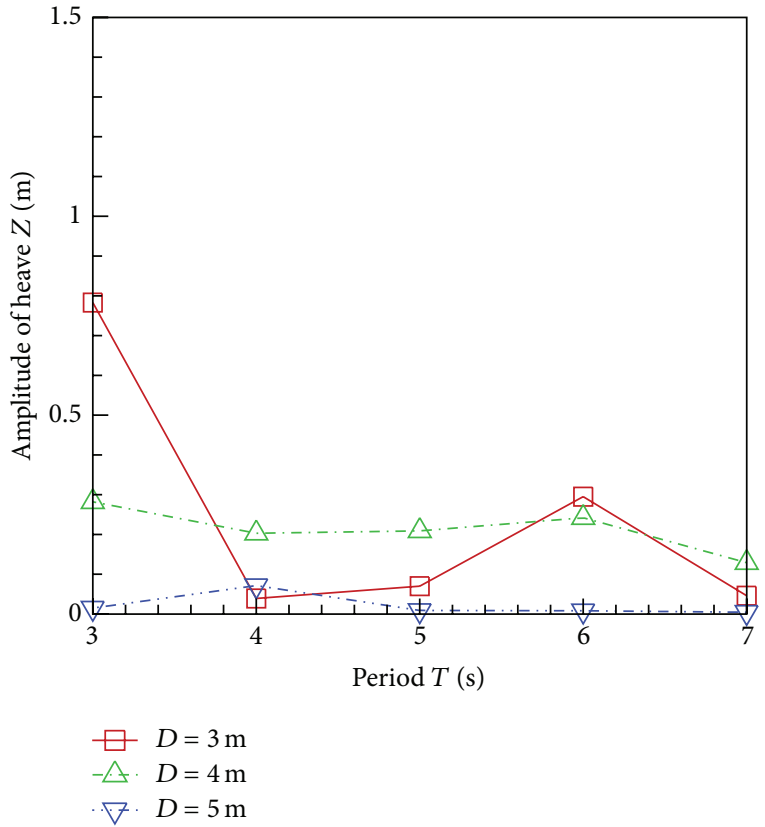

(b) Heave $Z$

FIGURE 5: Effects of damping plate diameters on mooring system stability.

4.2. Effects of Damping Plate Diameters. Damping plate is used to compete against the motion caused by the incident waves in order to give the appropriate stability of the mooring system. The diameter $D$ varies as $3.0 \mathrm{~m}, 4.0 \mathrm{~m}$, and $5.0 \mathrm{~m}$ and the height is fixed as $0.3 \mathrm{~m}$. Only one CWL links the clump weight and the single seabed weight. Operating wave height $H=0.5 \mathrm{~m}$ is used to deal with all five periods.

Effects of damping plate diameters on mooring stability are shown in Figure 5. Surge motions are represented by the maximum of surge offset values. Maximums of trough to crest height values in every period express corresponding heave motions. Data processing in the latter context as well as Figures 6 and 7 also follows the same principle as above. Sway motions and rotation displacements are observed to be very small under all calculated conditions and are not illustrated here. No obvious regularities of diameter effects have been found in the figures. In Figure 5(a), the surge amplitudes are mostly violent because the single vertical CWL is hard to restrain the horizontal motions. On the contrary, in Figure 5(b), the $5 \mathrm{~m}$ damping plate cooperating with the single CWL shows best performance to reduce the motions in the vertical direction. Therefore, $D=5 \mathrm{~m}$ is chosen to be the optimized diameter of the damping plate. Since the surge amplitudes under the condition $D=5.0 \mathrm{~m}$ exceed the presupposed criterion, diagonal taut lines should be installed to prevent large horizontal movements.

4.3. Effects of Taut Line System. Considering the performance of single CWL on the mooring system stability, two CWLs are proposed with twin seabed weights. The opening level of CWLs is represented by ratio $S / D$, varying from
0 to 1.0. Figure 6 illustrates effects of $S / D$ ratios on surge and heave motions. In Figure 6(a), it can be seen that the horizontal moving amplitudes become smaller as $S / D$ ratio increases. The reducing range also decreases as $S / D$ becomes greater. Two peaks could be observed at $T=4.0 \mathrm{~s}$ and $T=$ $6.0 \mathrm{~s}$. The surge amplitude is up to 0.65 at $T=4.0 \mathrm{~s}$ when $S / D$ ratio is zero, and it satisfies the criterion when $S / D$ is larger than 0.4 . The ratio $S / D=1.0$ shows the best performance to add the horizontal stability over the wave period range.

In Figure 6(b), the heave motions do not show any obvious distributing regularity according to $S / D$ ratio variation. It can be seen that most heaving values under small $S / D$ ratios are less than $0.1 \mathrm{~m}$, which fits the proposed mooring stability criterion in this paper. As $S / D$ increases, especially $S / D=1.0$, most values over the period domain approach or exceed $0.1 \mathrm{~m}$, which affects the surge motion oppositely. It is because larger $S / D$ ratios with greater opening angles will reduce the vertical tension under the same confined stress of wire ropes.

In order to deal with the paradoxical effects of $S / D=$ 1.0 on surge and heave motions, two SWLs are added to reduce the vertical motions obtained with only CWLs. In Figure 6(a), the coupled taut lines indeed show best performance on surge inhibitions and the amplitudes over the period domain decrease to less than $0.025 \mathrm{~m}$. On the other hand, effects on the heaving reduction are also evident and the indicating values are all less than $0.05 \mathrm{~m}$. Instead of setting additional vertical CWL and weights, the present design could utilize two seabed weights at maximum extent to control the costs. 


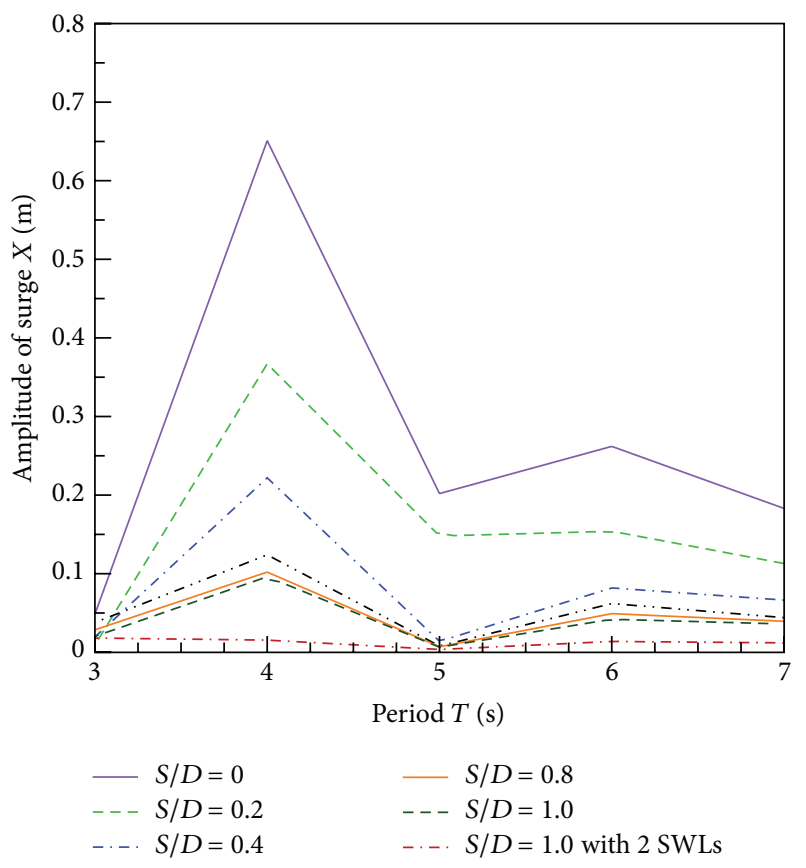

(a) Surge $X$

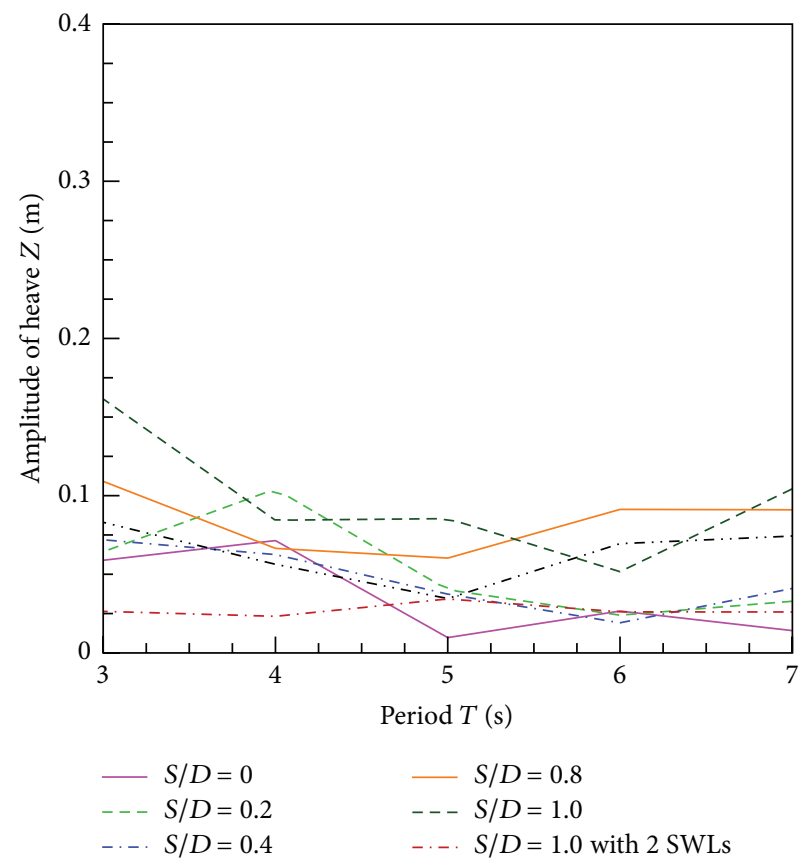

(b) Heave $Z$

FIgURE 6: Effects of $S / D$ ratio on mooring system stability.

4.4. Effects of Incident Wave Directions. Since the layout of taut lines is designed to be parallel to the incident wave direction, it is necessary to study the operating performance of the mooring system under oblique waves. Two angles are employed as $45^{\circ}$ and $90^{\circ}$ in Figure 7(a), which are defined as included angles between incident wave directions and the layout line of CWLs and SWLs. $H=0.5 \mathrm{~m}$ is still employed as the operating wave height. Figures 7 (b) to 7 (c) display effects of incident wave directions on mooring system movements in horizontal and vertical directions.

In Figure 7(b), sway amplitudes become significantly greater as expected when the incident angle increases. Most calculated results under oblique waves exceed $0.2 \mathrm{~m}$ for surge motion. A peak also can be found at $T=5.0 \mathrm{~s}$ for both $45^{\circ}$ and $90^{\circ}$. The maximum value is 0.88 , which is over 4 times higher than the criterion value. For surge motions in Figure $7(\mathrm{c})$, the amplitudes under various wave conditions are all less than $0.05 \mathrm{~m}$, which will not affect the buoy operation obviously under oblique waves. Although heave motions are not increased as sharply as sways in Figure 7(d), their effects on the operating performance of oscillating buoys WEC are more sensitive. Therefore, it can be seen that current design of mooring system cannot compete with oblique waves as well as waves from the forward direction. If at least two mean directions are employed in the design, it can be imagined that cross arrangement of two sets of CWLs and SWLs will provide a good performance to confront waves from various directions.
4.5. Tension Analysis. Tensile forces on the taut lines are calculated under extreme wave conditions $(H=1.4 \mathrm{~m})$ with three incident wave directions. The mooring system is as follows: 2 SWLs and 2 CWLs, $S / D=1.0$. The maximum values under each condition are extracted from time histories of tension forces on all taut lines, which occurs mostly on the left CWL in Figure 2. The above values under various incident directions are illustrated in Figure 8. It can be seen that maximum tensions occur at $T=4.0 \mathrm{~s}$ for all wave conditions and they decrease sharply as the wave period increases. Although maximum tensions under all extreme wave conditions do not exceed the allowed value of $138 \mathrm{kN}$, the tensile forces have approached this limit at $T=4.0 \mathrm{~s}$, which should be noted in the further design for more security space.

\section{Conclusions}

A small oscillating wave energy converter has been designed for electricity supply of nearshore ocean buoys. The mooring system utilizes wire ropes as taut lines to connect the damping plate and clump weight with seabed weights, which are investigated numerically to provide stationary state for heaving buoy operation. Ansys-AQWA was used to deal with the potential flow, waves, and fluid structure interactions in the time domain.

It has been found that the damping plate could provide a good station-keeping for the energy converting 

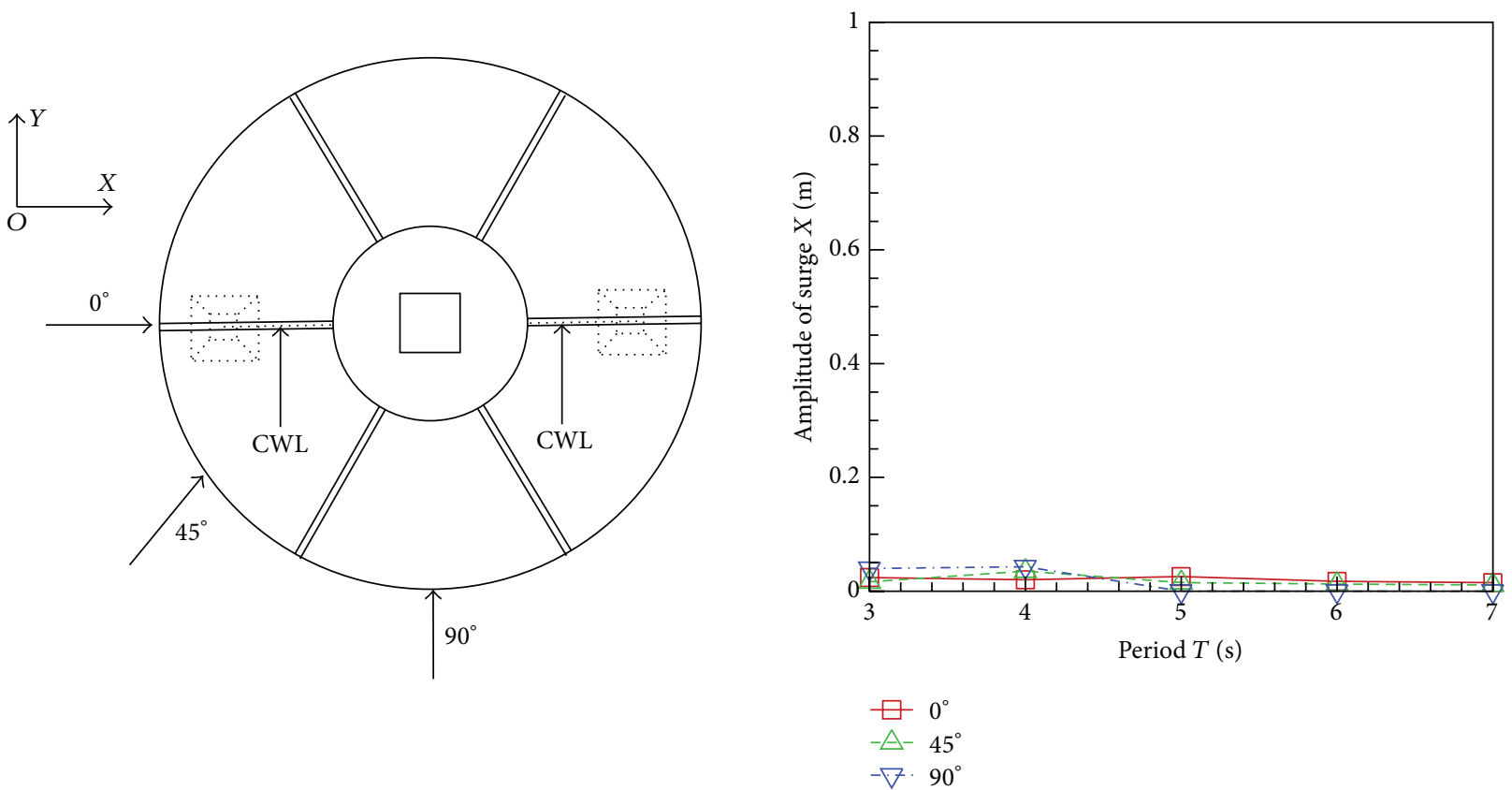

(a) Incident angles of oblique waves

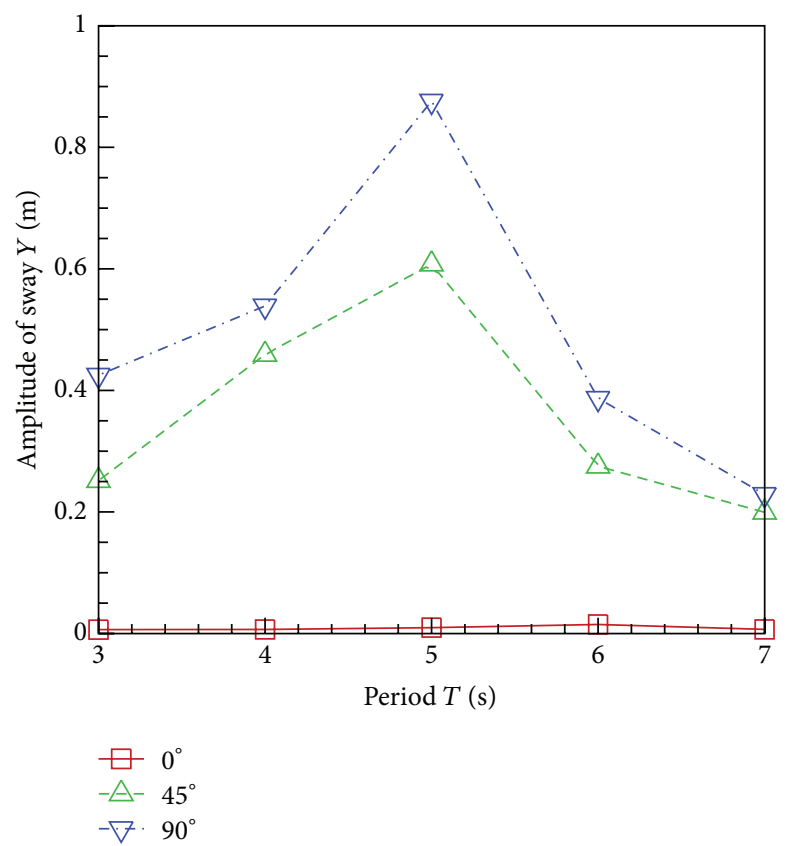

(c) Sway (b) Surge $X$

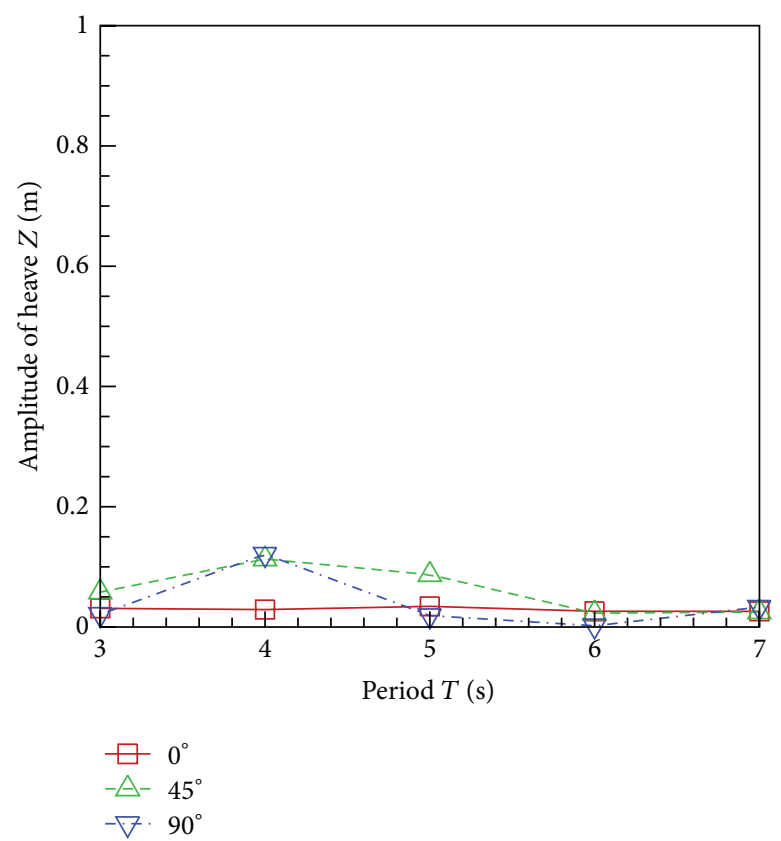

(d) Heave Z

FIGURE 7: Effects of incident wave direction on mooring system stability.

compartment. Under the current design parameters, the diameter $D=5.0 \mathrm{~m}$ of the damping plate with single CWL shows best restraining results on the heaving motion of the mooring facilities, which also needs more support to control the surge. Twin CWLs are then investigated and the ratio $S / D=1.0$ can significantly reduce the surge motion and two added SWLs could help to reduce both surge and heave amplitudes. Oblique wave testing results suggest adding the cross arrangement of CWLs and SWLs to deal with more incident wave directions. Calculated tensile forces on the taut lines demonstrate that the present design satisfies the allowed tension criterion.

All the above results show that the mooring system utilized and optimized here is feasible and reliable. In the future, more detailed design is to be carried out for the prototype machine manufacture. Through rough calculations, the costs 


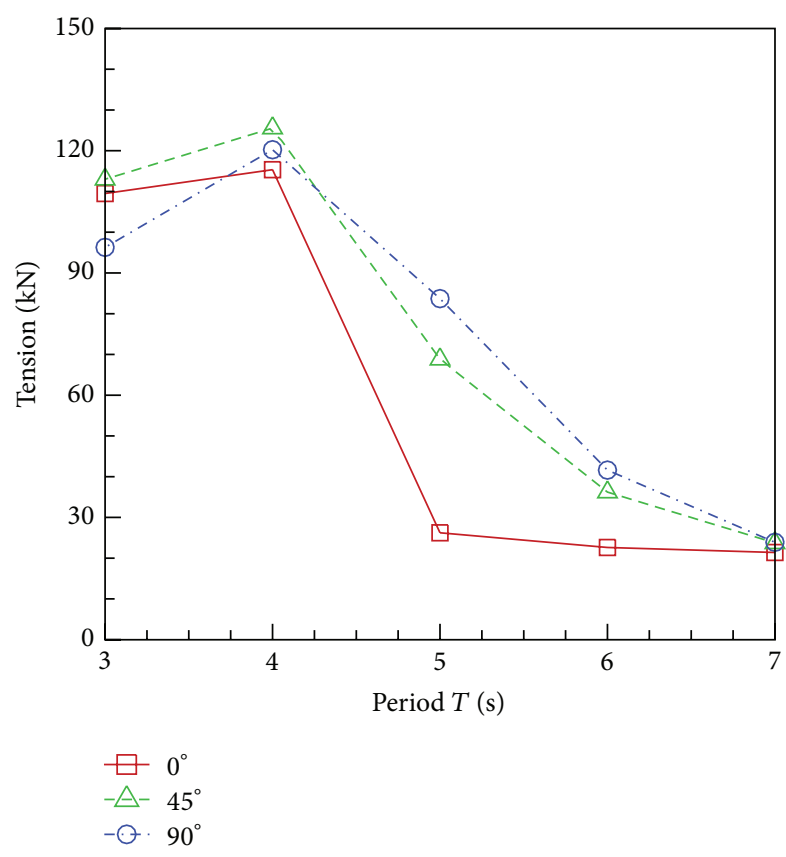

FIgURE 8: Tension forces on taut lines under extreme wave conditions.

of the present mooring system are about $40 \%$ lower than those of the traditional 4 or 5 points mooring system. Sea trials will be conducted in order to test the station-keeping capability of the present mooring system.

\section{Conflict of Interests}

The authors declare that there is no conflict of interests regarding the publication of this paper.

\section{Acknowledgments}

The authors are grateful to the financial support provided by National Natural Science Foundation of China (41376100), National High Technology Research and Development Program of China (863 Project, 2012AA052601), Special Fund for Ocean Renewable Energy of SOA (QDME2011GD02), Shandong Natural Science Funds for Distinguished Young Scholar (JQ201314), Qingdao Municipal Science \& Technology Program (13-4-1-38-hy), and the Program of Introducing Talents of Discipline to Universities (111 Project, B14028).

\section{References}

[1] E. B. Agamloh, A. K. Wallace, and A. von Jouanne, "Application of fluid-structure interaction simulation of an ocean wave energy extraction device," Renewable Energy, vol. 33, no. 4, pp. 748-757, 2008.

[2] Y.-H. Yu and Y. Li, "Reynolds-Averaged Navier-Stokes simulation of the heave performance of a two-body floating-point absorber wave energy system," Computers \& Fluids, vol. 73, pp. 104-114, 2013.

[3] A. Umar and T. K. Datta, "Nonlinear response of a moored buoy," Ocean Engineering, vol. 30, no. 13, pp. 1625-1646, 2003.
[4] R. Guanche, V. Gómez, C. Vidal, and I. Eguinoa, "Numerical analysis and performance optimization of a submerged wave energy point absorber," Ocean Engineering, vol. 59, pp. 214-230, 2013.

[5] Z.-M. Yuan, A. Incecik, and C. Y. Ji, "Numerical study on a hybrid mooring system with clump weights and buoys," Ocean Engineering, vol. 88, pp. 1-11, 2014.

[6] G. Benassai, A. Campanile, V. Piscopo, and A. Scamardella, "Mooring control of semi-submersible structures for wind turbines," Procedia Engineering, vol. 70, pp. 132-141, 2014.

[7] V. Harnois, S. D. Weller, L. Johanning et al., "Numerical model validation for mooring systems: method and application for wave energy converters," Renewable Energy, vol. 75, pp. 869-887, 2015.

[8] E. E. Bachynski, Y. L. Young, and R. W. Yeung, "Analysis and optimization of a tethered wave energy converter in irregular waves," Renewable Energy, vol. 48, pp. 133-145, 2012.

[9] V. Krivtsov and B. Linfoot, "Disruption to benthic habitats by moorings of wave energy installations: a modelling case study and implications for overall ecosystem functioning," Ecological Modelling, vol. 245, pp. 121-124, 2012.

[10] P. C. Vicente, A. F. D. O. Falcão, L. M. C. Gato, and P. A. P. Justino, "Dynamics of arrays of floating point-absorber wave energy converters with inter-body and bottom slack-mooring connections," Applied Ocean Research, vol. 31, no. 4, pp. 267-281, 2009.

[11] E. Vijayakrishna Rapaka, R. Natarajan, and S. Neelamani, "Experimental investigation on the dynamic response of a moored wave energy device under regular sea waves," Ocean Engineering, vol. 31, no. 5-6, pp. 725-743, 2004.

[12] C. Ji and Z. Yuan, "Experimental study of a hybrid mooring system," Journal of Marine Science and Technology, vol. 20, no. 2, pp. 213-225, 2015.

[13] S. Ambühl, M. Sterndorff, and J. D. Sørensen, "Extrapolation of extreme response for different mooring line systems of floating wave energy converters," International Journal of Marine Energy, vol. 7, pp. 1-19, 2014.

[14] J. Fitzgerald and L. Bergdahl, "Including moorings in the assessment of a generic offshore wave energy converter: a frequency domain approach," Marine Structures, vol. 21, no. 1, pp. 23-46, 2008.

[15] P. R. Thies, L. Johanning, V. Harnois, H. C. M. Smith, and D. N. Parish, "Mooring line fatigue damage evaluation for floating marine energy converters: field measurements and prediction," Renewable Energy, vol. 63, pp. 133-144, 2014.

[16] Ansys, AQWA Theory Manual. Release 15.0, Ansys, Canonsburg, $\mathrm{Pa}, \mathrm{USA}, 2013$.

[17] Ansys, AQWA-LINE Manual. Release 14.5, Ansys, Canonsburg, $\mathrm{Pa}, \mathrm{USA}, 2012$.

[18] Ansys Inc, AQWA-NAUT Manual, Release 14.5, 2012.

[19] Standardization Administration of People's Republic of China, National Code of PRC, Steel Wire Ropes for Important Purposes, GB8918-2006, Standardization Administration of People's Republic of China, 2006.

[20] Q. Na, Study on hydrodynamic performance of oscillating buoy WEC considering power take-off system [M.S. thesis], Ocean University of China, Qingdao, China, 2015 (Chinese). 


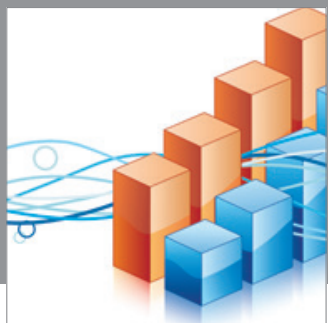

Advances in

Operations Research

mansans

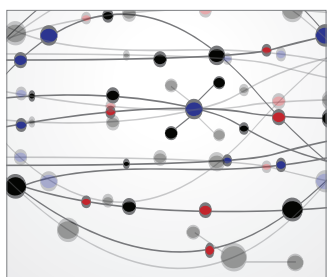

The Scientific World Journal
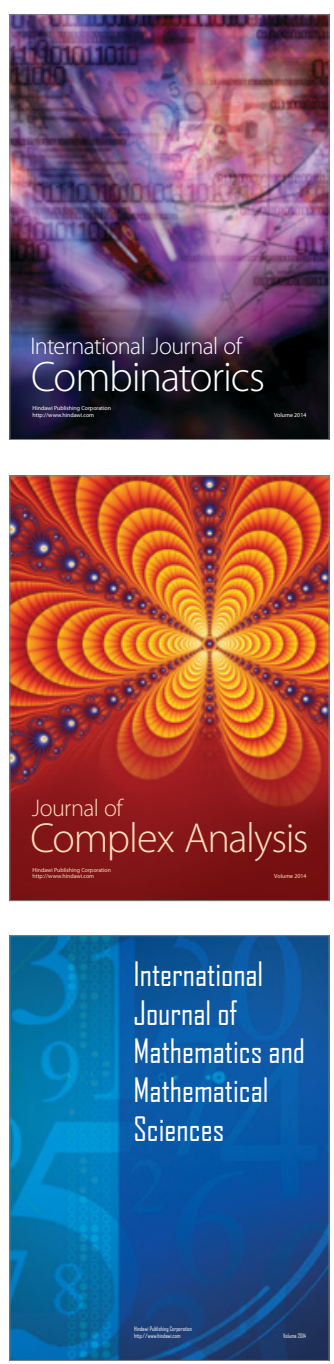
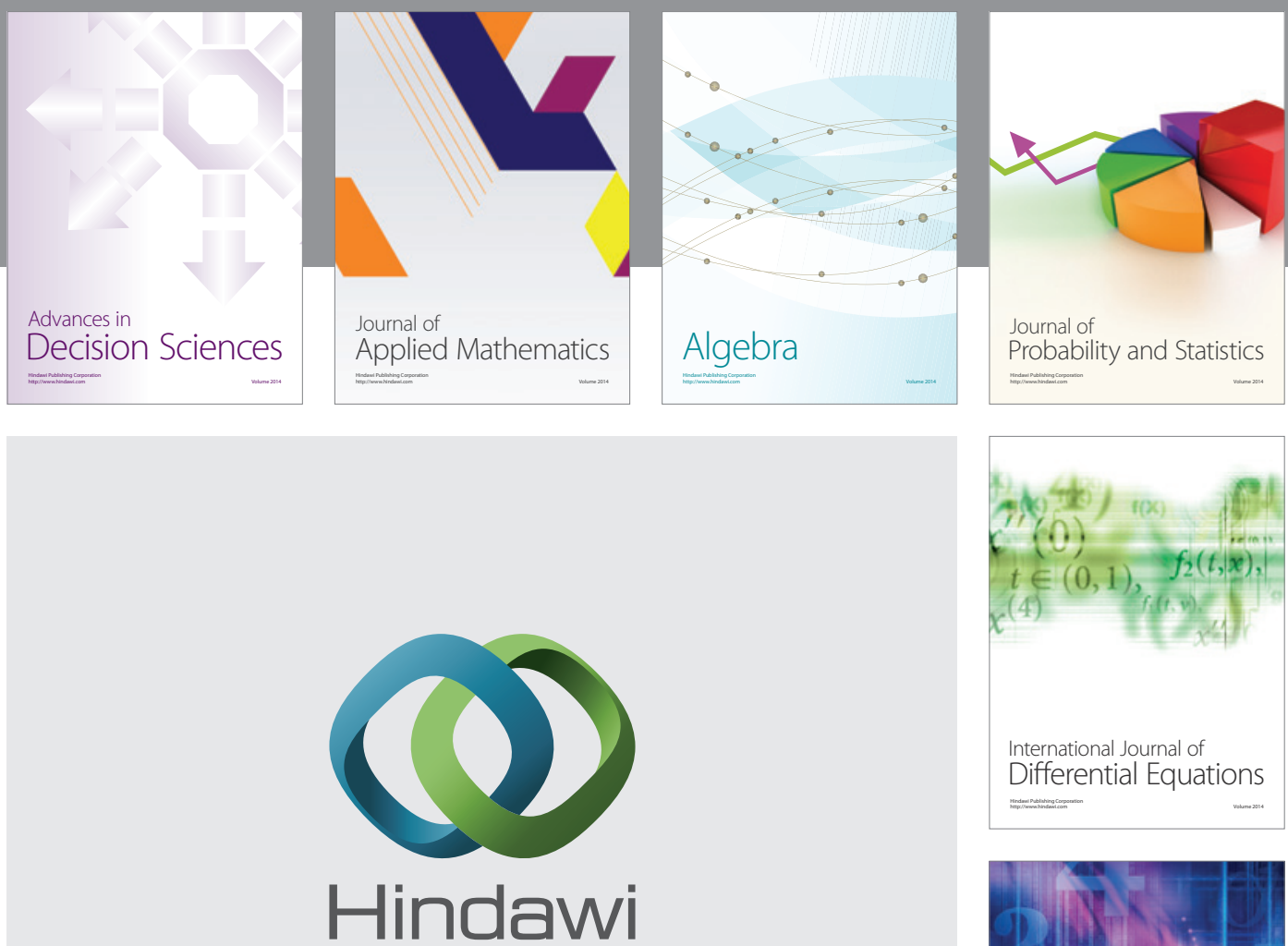

Submit your manuscripts at http://www.hindawi.com
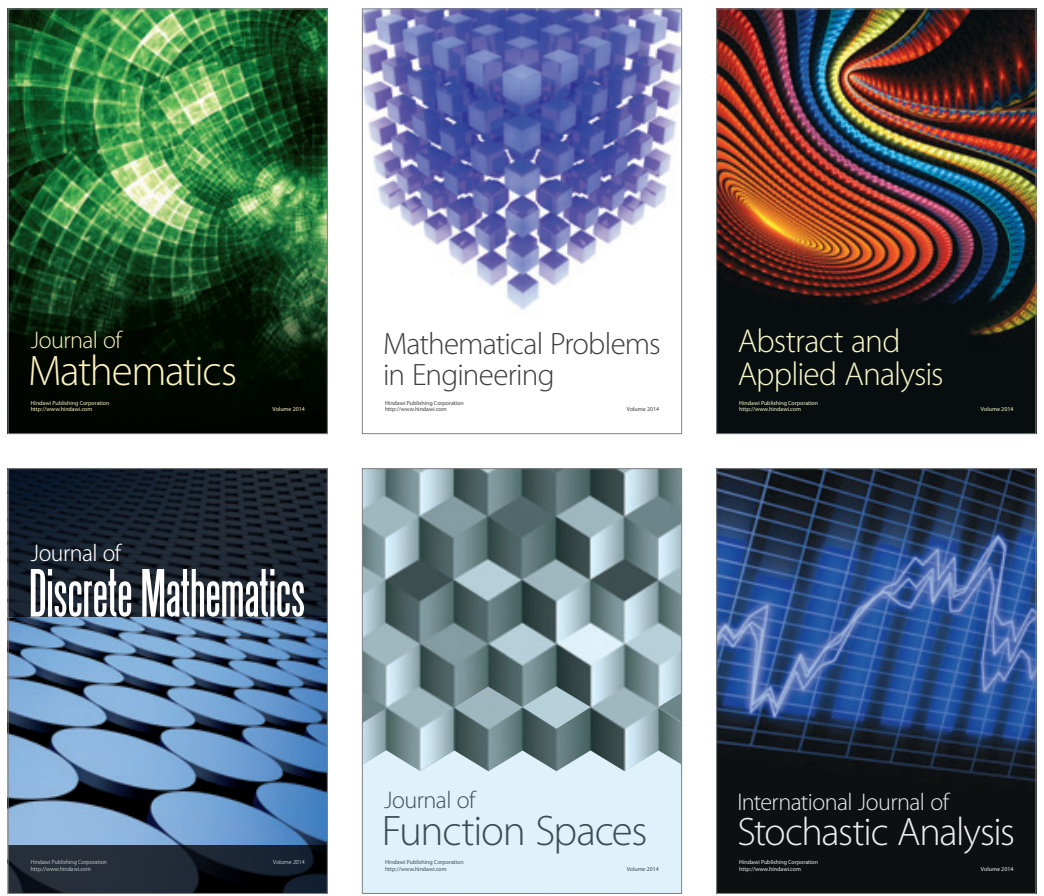

Journal of

Function Spaces

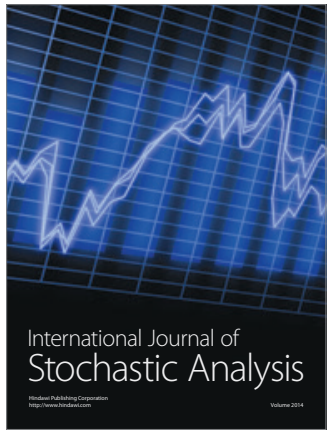

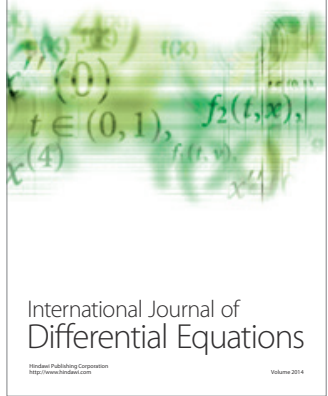
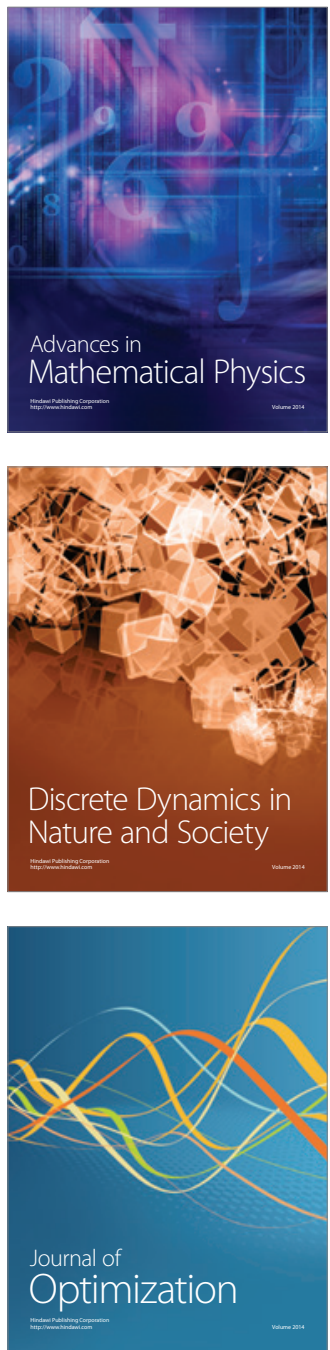